\title{
When authorship met authenticity
}

\author{
As counterfeit drugs abound, Adrian Johns recalls how medical patenting was created in the \\ seventeenth century to secure trust across growing international trade networks by quashing fakes.
}

\begin{abstract}
Adrian Johns
Pharmaceutical counterfeiting is on the rise. In 2005, the Organisation for Economic Co-operation and Development. based in Paris, reported the emergence of fakes of even specialized medicines for the most chronic and serious conditions such as cancer, AIDS, diabetes and Alzheimer's disease, as well as ubiquitous antibiotics and weight-loss pills. Widely distributed in Africa and the developing world, such counterfeits have become increasingly common in Europe and North America with the growth of Internet pharmacies.

Counterfeit drugs can be dangerous.
\end{abstract} They may have the wrong ingredients, or the right ones in the wrong concentrations. More than 100 Panamanians were killed in 2007 by copycat cough syrup. Fake anti-malarials led to the death of a renowned conservation biologist in Cambodia in 1999 (Nature 434, 132-136; 2005). Individual patients cannot generally tell whether a drug is fake or not, even if they are aware of the possibility. On a community level, counterfeits can make it difficult to test if a drug actually works, or, by under-dosing, generate increased microbial resistance to genuine drugs (M. D. Green J. Postgrad. Med. 52, 288-290; 2006).

Pharmaceutical counterfeiting is an unwelcome by-product of globalization, and demands a commensurately global response. For example, concern has become so acute that, in May 2005, the World Health Organization created a Rapid Alert System for combatting counterfeit drugs, modelled on those for epidemics such as bird flu. And in November 2006 the organization established IMPACT (the International Medical Products Anti-Counterfeiting Taskforce) to seek global solutions.

Yet in some senses globalization is actually returning us to what was the historical norm. For most of human history there was fear of adulteration, rather than confidence in its absence. Ancient authorities such as Dioscorides, Theophrastus and Galen warned of the risks of ill-prepared medicines. In the days of William Harvey and Isaac Newton, physicians were accustomed to warning against apothecaries' deceptions. Leading members of London's Royal College of Physicians believed that anyone who trusted "Apothecaries, and common Chymists" was placing their life in the hands of "as great cheats as are now Extant in the World." And in the Enlightenment a

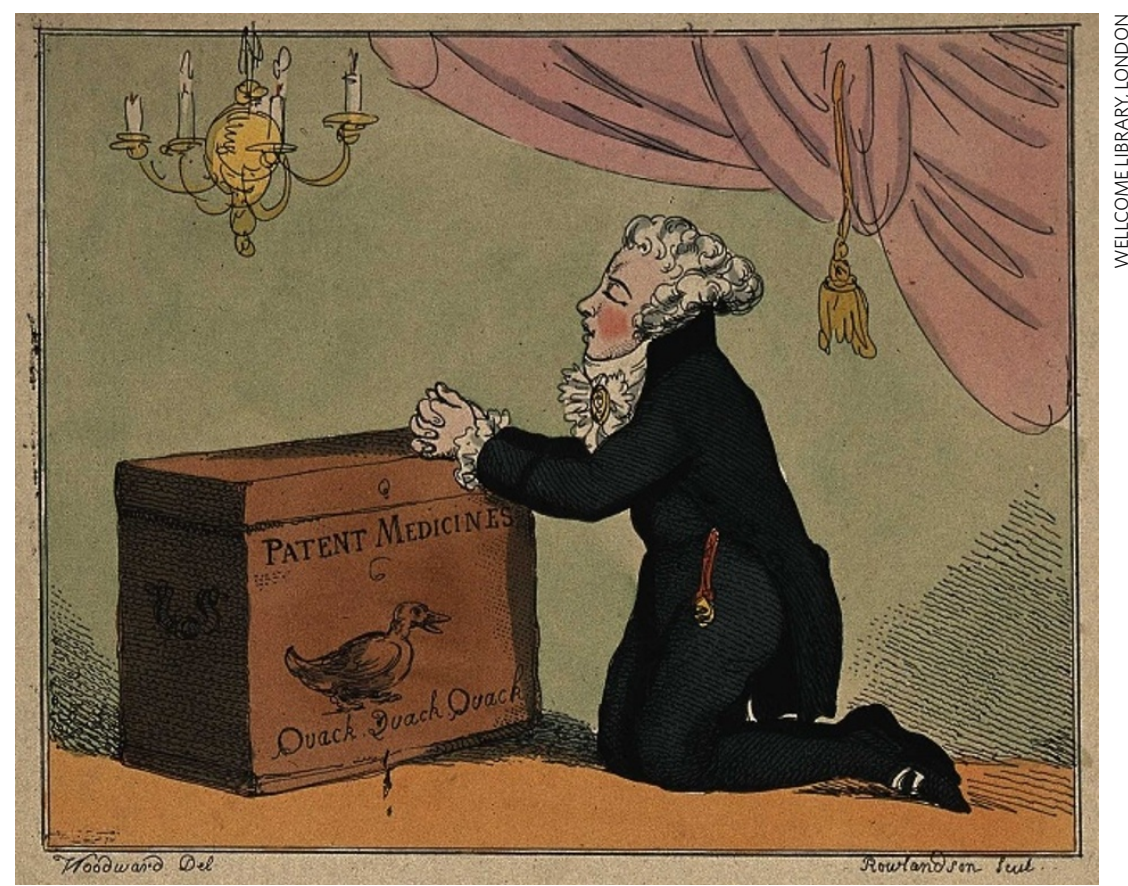

By the nineteenth century the pharmaceutical marketplace was less anarchic than before.

new generation of experts warned that the pharmaceutical marketplace was, in the words of botanist J. E. Gilibert, "anarchic".

It was in this fraught setting that the basis for modern medical patenting was laid, complete with the debates that still dog the issue.

\section{Log books}

Various solutions were tried. Pharmacopoeias - official books listing recognized medicinal substances - had long existed. In 1618 the Royal College of Physicians issued the first national one, largely to police the pharmaceutical marketplace. It did not work. Pharmacopoeias were easy to pirate and to misuse. In 1690 Robert Boyle tried a different tack. He suggested in Medicina Hydrostatica that measuring specific gravities with a precision balance could reveal counterfeits. The proposal did not catch on. Neither rules nor technology did much to stop the flourishing of what French pharmacist A. P. Favre later called "pharmaceutical piracy."

Meanwhile France, England and the Netherlands were competing to establish global trading empires. Such international commerce depended on trust at a distance. Remote merchants, doctors and patients had to be confident in the authenticity of the goods being shipped. If medicines were untrustworthy even in London or Paris, what could the burgeoning empires do?

The answer proved to lie not in a regulatory code, nor in a machine, but in the assertion of authorship. It was an extension of the idea that one would trust a drug if one has seen the person who ground it up and handed it over. This solution drew on practices that had been developed to establish experimental science itself as the new universal learning.

At the Royal Society of London, founded in the early 1660s, experimenters had developed authorship and publication protocols to secure and protect discoverers and inventors. They sought to manage priority disputes, and to encourage participants to communicate new discoveries.

For example, the Society had established a register in which contributions were logged as they arrived, with dates and detailed descriptions. Inventions could be locked away in the Society's repository, and mathematical theorems lodged in code to safeguard them. The idea was to establish the Society as a 'bank' for what we now call science, to which contributors from continental Europe and the colonies could trust their reputations. In 1665 the Society also launched the first scientific journal, the Philosophical Transactions, as a public counterpart to this system. Experimental 
philosophy became a self-perpetuating international endeavour. Its protocols became mainstays of the scientific enterprise itself.

\section{Privileged few}

Patents were different. Invented in the middle ages, a patent or 'privilege' was a legal document, issued by the king, extending state control over some economic goods such as steel, gunpowder or soap. Patents had long been controversial tools for rewarding favoured courtiers and tradesmen. In 1624, the English Parliament sought to limit them by passing the Statute of Monopolies, which ratified the use of patents only in cases of new inventions. This became the origin of all later intellectual-property law in the Englishspeaking world.

In practice, to obtain a patent for a new device was labyrinthine, expensive and uncertain. There was no such thing as a patents system in Britain until the mid-nineteenth century, long after it had been created in the United States and, in a very different way, in France. There were isolated examples of patents on medical devices such as baths and distillation techniques. And some substances such as guaiac (imported from the New World and reputedly effective against syphilis) were privileged. But nobody seems to have sought a patent on a new pharmaceutical substance as such.

This makes it all the more interesting that the man who introduced pharmaceutical patenting to the English-speaking world was also responsible for maintaining the nascent protocols of experimental science. In effect, he created the modern alliance between authorship and authenticity in pharmaceuticals.

\section{Grew knew}

That man was Nehemiah Grew (16411712). Grew was a physician and advocate of, in his words, the anatomy and physiology of plants. Grew owed his reputation and livelihood to the Royal Society's authorship and publication system, which had secured his early botanical researches against potential rivals on the continent. He became Secretary of the Society in 1677, and for a few years took over the management of its all-important international correspondence network and the Philosophical Transactions. Then Grew saw a chance to make his fortune. He began to manufacture and sell a "bitter purging salt" with the medicinal virtues of the spa water at Epsom, to which London's fashionable elite were then thronging. He hired an 'operator' (loosely, a foreman) named Thomas Trammel and set up a factory to mass-produce 'Epsom salts'.

Almost immediately Grew faced competition. A pair of brothers, Francis and George Moult, apothecaries both, set up their own Epsom-salts plant, and an extraordinary feud ensued. At its height, it implicated the public authority of the Royal Society and the Royal College of Physicians. Grew's camp called their rivals' salt a counterfeit. The Moults countered they stood for freedom of knowledge and accused Grew of being a monopolist. Grew's side responded that the competing salt was not just fake, but poisonous. It had already killed its first victim, they charged: an unfortunate Irish bishop.

First Grew tried to use the Royal Society's protocols to defend his enterprise. $\mathrm{He}$ appealed to its log of his own claim to priority. The Moults were unrepentant.

His next move was momentous. In 1698 he obtained a patent on his manufacturing technique from the royal court at Whitehall. It was not the first privilege on a medicine, but it does seem to have been the first on the basis of a medicine being an invention. Grew then transferred the patent to a friend and fellow physician Josiah Peter, who published a book mounting a vigorous defence of the inventor's right - and of the very principle of pharmaceutical patenting.

\section{Confidence trick}

Peter's defence, Truth in opposition to ignorant and malicious falshood [sic], is perhaps the single most important forgotten document in the history of 'intellectual property' in pharmaceuticals. Circulated in 1701 , it advanced the first public argument for such property. Its rationale was precisely the phenomenon of trust that is now once again under such strain. It claimed, in short, that medical patenting must be created in order to secure confidence in the authenticity of medicines across international trade networks. Empires could be built on it.

Peter argued that Grew's salts could become a valuable commodity, and an economic asset to the British realm. This could only happen, he urged, if the preparation could be trusted abroad, as well as at home. A patent, Peter proposed, was the way to secure that trust. With a patent inhibiting imitators, the salts would benefit from trust at a distance, and a major new international business would surely come into being. Without one, "counterfeit salts" would jeopardize trade by destroying the reputations of any merchants who dealt in them.

Peter lost his fight over Epsom salts. The Moults continued to make and sell their copycat product. But a major step had been taken. Pharmaceutical patents began to increase soon after. The next one in
England arrived in 1711, and more followed in a steady and growing stream. After the American Revolution, when the newly independent United States quickly established a legal machinery for issuing and policing patents, the practice expanded rapidly there too.

A national and international medical marketplace arose. The rules melded authorship and authenticity to secure both. They were premised neither on a Lockean philosophy of property (title being created by the application of labour) nor on a principle of Romantic genius (title deriving from the emanation of some uniquely individual creativity) - the two alternatives that we tend to invoke. Instead, those rules originated in the quest to establish genuineness. So it was that the alignment between trust and trade became foundational to the modern patenting regime in pharmaceuticals.

Today this alignment is once more cast into doubt. Again we face the problem of guaranteeing the identity of pills and powders across trade networks that extend far beyond national policing regimes. The dangers are real, and much greater than in pre-industrial Europe. Nonetheless, Grew's misfortune is worth
recalling for two reasons. First, that the very idea of pharmaceuticals as authorial properties arose from a need to connect trade, empire and trust across global distances. Second, that the principle of medical authorship reflected the practical conventions from which modern science itself emerged.

In other words, the forceful return of counterfeits spotlights tensions that are implicit in science and trade from their origins in the early modern period. What came into existence then was a medical marketplace for which patents provided principal ground-rules. They did not eliminate counterfeiting, of course, and patented drugs were never the only ones counterfeited, as remains the case today. Yet with authenticity brought into alignment with authorship by patenting, a system arose in which trust could persist at a distance - and both the trade and science of medicines could become global. The credibility of this system itself could only endure with constant policing. That too remains true today. The question for us is this: will the challenge of counterfeiting in a truly global economy force the protocols of scientific authorship and authenticity to change just as fundamentally all over again?

Adrian Johns is professor of history at the University of Chicago, 1126 East 59th Street Chicago, Illinois 60637, USA. His new book Piracy will be published by the University of Chicago Press. 